\title{
Pazopanib Induced Hand-Foot Syndrome in a Patient Previously Treated with Sunitinib: A Possible Cumulative Skin Toxicity?
}

\author{
Emanuele Cozzani' ${ }^{1}$, Sanja Javor ${ }^{1}$, Stefano Ottoboni' ${ }^{2}$, Aurora Parodi ${ }^{1}$ \\ ${ }^{1}$ Department of Endocrinological and Metabolic Sciences, Section of Dermatology, University of Genoa, Genoa, \\ Italy \\ ${ }^{2}$ Department of Chirurgic and Diagnostic Sciences (DISC), University of Genoa, Genoa, Italy \\ Email: javor.med@gmail.com
}

Received 24 June 2016; accepted 27 August 2016; published 30 August 2016

Copyright (C) 2016 by authors and Scientific Research Publishing Inc.

This work is licensed under the Creative Commons Attribution International License (CC BY).

http://creativecommons.org/licenses/by/4.0/

c) (i) Open Access

\begin{abstract}
Hand-foot syndrome (HFS), also known as palmar-plantar erythrodysesthesia, is a skin toxicity that could be observed during target therapies such as with tyrosine-kinase inhibitors (TKI). It usually develops within the first 2 - 4 weeks of drug administration. We present a case of HFS induced by Pazopanib after 2 months of treatment, in patients previously treated with Sunitinib, suggesting a possible cumulative toxicity of two drugs. The clinical and therapeutic management of skin adverse reactions during TKI therapy usually requires $25 \%$ dose reduction and adequate local treatment. It is important for the clinicians to recognize clinical signs and symptoms of such skin toxicities. Attention should be paid especially when two or more drugs from the same class are used in combined treatment.
\end{abstract}

\section{Keywords}

Hand-Foot Syndrome, Pazopanib, Sunitinib, Tyrosine-Kinase Inhibitors, Cumulative Toxicity

\section{Introduction}

Sunitinib and Pazopanib are the most prescribed targeted therapies for the systemic management of advanced renal cell carcinoma (RCC). Sunitinib is employed in first-line treatment of RCC [1]. Since members of the cdk and cyclin family were reduced in parallel, modifications of the cdk-cyclin axis (particularly cdk1-cyclin B and cdk2-cyclin A) may be one mechanism by which Sunitinib exerts its antitumour effect. Sunitinib up-regulated also p19 and p27, directly associated with advanced disease and reduced cancer specific survival in RCC cells [2] 
[3]. Pazopanib is second-generation potent inhibitor of multiple protein targets involved in tumor cell proliferation and angiogenesis. In this process, several proangiogenic factors are involved, with a central role for the vascular endothelial growth factor (VEGF) family. Inhibition of this pathway has demonstrated antitumor activity in several tumor types, including renal cell carcinoma [4]. Pazopanib inhibits this signaling pathway via ATP-competitive inhibition of VEGFR-1, VEGFR-2, and VEGFR-3. Similar activity has been demonstrated against platelet-derived growth factor receptor (PDGFR)- $\alpha$, PDGFR- $\beta$, fibroblast growth factor receptor (FGFR)-1, FGFR-3, and c-Kit [5]. Cutaneous adverse effects are among the most frequently observed toxicities with many targeted agents, and their intensity can be dose-limiting or lead to therapy discontinuation [6]. Hand-foot syndrome (HFS), also known as palmar-plantar erythrodysesthesia, is a frequently seen skin toxicity associated with chemotherapeutic agents like 5-fluorouracil, capecitabine and tyrosine-kinase inhibitors (TKI) like Sunitinib; less commonly with Pazopanib. Data from the literature are variable and indicate that $9 \%-62 \%$ of studied patients receiving TKI develop HFS usually within the first 2 - 4 weeks of drug administration [7] [8]. We present a case of HFS induced by Pazopanib after 2 months treatment, in a patient previously treated with Sunitinib.

\section{Case Report}

A 52-year-old female patient was diagnosed as a case of left renal cell carcinoma (clear cell histology) in 2002. In 2014, metastasis were detected, she started treatment with TKI Sunitinib $50 \mathrm{mg}$ daily. After 3 months of treatment, the patient complained of gastrointestinal problems, so Sunitinib was interrupted. Pazopanib $800 \mathrm{mg}$ daily was started. After two months of treatment, the patient reported desquamation of the hands and soles. She was initially treated with topical urea $40 \%$ with temporary benefit. Six months later, because of the persistence of gastrointestinal symptoms and worsening of skin manifestations with painful, erythematous and hyperkeratotic lesions of palms and soles compatible with HFS of grade 2, the treatment with Pazopanib was reduced by $25 \%$ (Figure 1, Figure 2). Treatment with topical urea $40 \%$ cream, clobetasol $0.05 \%$ ointment and $2.5 \%$ lidocaine was prescribed. After 3 months, at the follow-up, the patient showed complete resolution of the plantar manifestations and only a slight residual hyperkeratosis of the sole. Furthermore, the renal cell carcinoma was under remission.

\section{Discussion}

Clinically, HFS presents as symmetric erythematous lesions on skin surfaces exposed to repeated pressure or friction (Table 1). All grades (1-3) and high-grade (grade 3) HFS reaction have been variably reported in 6\% $19 \%$ of patients treated with Sunitinib [8].

The pathogenesis of HFS is poorly understood. Although there is no consensus that different causative drugs share a single underlying mechanism, current evidence suggests an underlying direct toxic effect as the most likely cause. The predilection of HFS for the palms and soles may be due to the high concentration of eccrine

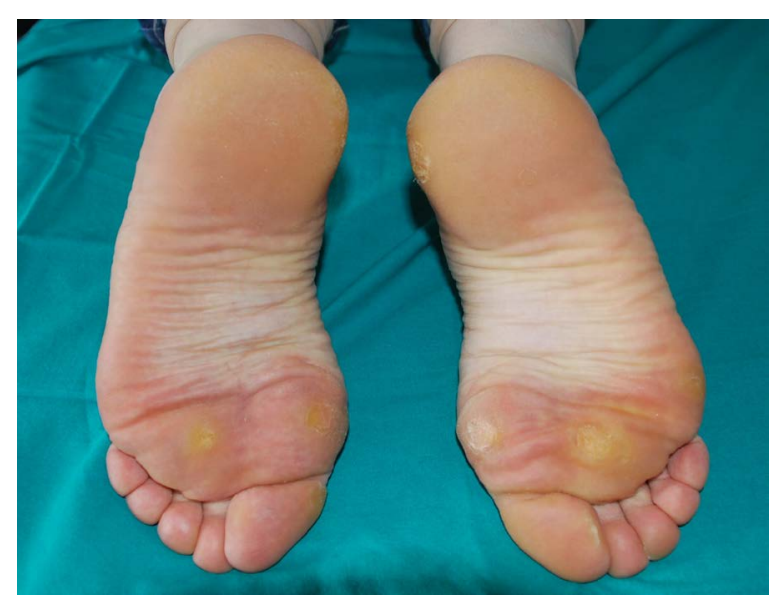

Figure 1. Erythematous and hyperkeratotic lesions of the soles. 


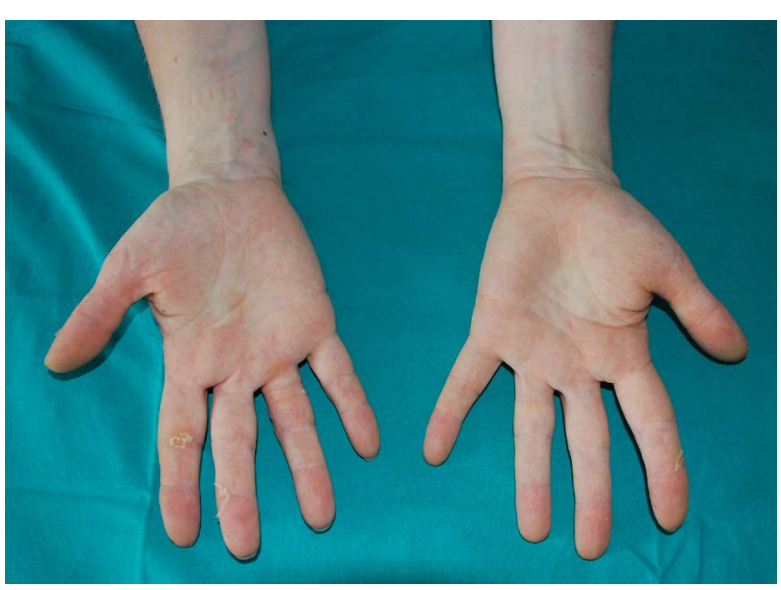

Figure 2. Erythema and desquamation of the palms.

Table 1. Clinical classification and management for all grade HFS.

\begin{tabular}{|c|c|c|}
\hline Grade & Syptoms & Management \\
\hline 1 & Minimal skin changes without pain & Emollients and keratolytics \\
\hline 2 & Skin changes with pain limiting activities of daily living & $\begin{array}{c}\text { + Topical steroids (class I/II) and topical anesthetics, } \\
\text { nonsteroidal anti-inflammatory drugs }\end{array}$ \\
\hline 3 & Severe skin changes with debilitating pain limiting self-care & + Antiseptic soaks; treatment interruption \\
\hline
\end{tabular}

ducts in these areas. It is possible that the tick stratum corneum of the palms and soles acts as a reservoir, as hypothesized for the doxorubicin-associated HFS [9]. Furthermore, capillary microtrauma at sites predisposed to mechanical and frictional stress, such as hands, feet, axillae, and intertriginous areas with consequent extravasation of the drug into surrounding tissue should be an explanation of HFS. The presence of target molecules as TKI may lead to major oxidative damage and local production of toxic free radicals and induce apoptosis of keratinocytes. There are very few studies reporting Pazopanib-induced HFS. However, the reported cases of HSF are generally described only for the single drug therapy, and the possible cumulative toxicity of these agents is not reported in the literature.

Although skin toxicity associated with Pazopanib is less reported than with Sunitinib [7] [8]. In our patient, who received both Sunitinib and Pazopanib, drug-induced reaction was temporary more related to the second one. It should be important to clarify, in these cases treated with both Sunitinib and Pazopanib, if the first one induced delayed adverse skin reaction or the second one, Pazopanib, plays a role in direct skin toxicity. Furthermore, we suggest that both drugs take part in the HFS induction probably due to cumulative skin toxicity.

It is possible that these toxicities could represent a delayed reaction or may arise with the introduction of a second drug from the same class.

The clinical and therapeutic management of skin adverse reactions during TKI therapy usually requires $25 \%$ dose reduction and adequate local treatment. It is important for the clinicians to recognize clinical signs and symptoms of such skin toxicities. Attention should be paid especially when two or more drugs from the same class are used in combined treatment or subsequently as in our case. There are no measures available used to prevent the Pazopanib and Sunitinib’s cumulative toxicity so, more attention should be paid to cutaneous side effects or others such as gastrointestinal side effects and we are conscious that this is a single case of HFS but we suggest the clinicians to evaluate a possible cumulative toxicity of drugs with the same pharmacologic target.

\section{Conclusion}

Sunitinib and Pazopanib are among the most prescribed targeted therapies for the systemic management of advanced RCC but with only a partial response. At the moment several therapeutic agents showed promising pharmacodynamic effects and have been tested with success in preclinical models of RCC and are therefore awaiting clinical evaluation. Particularly, dual inhibitors of PGAM1 and 6-PGDH (e.g., PGMI-004A) and inhi- 
bitors of the relatively cancer-specific target PFK-FB3 such as PFK15 warrant further investigation [10]. All grades HFS reactions have been variably reported in patients treated with Sunitinib and Pazopanib [8]. Handfoot syndrome may represent a challenge regarding its causative agent but it is important to consider possible cumulative toxicities in cases of sequential administration of the drugs from the same class. Therefore, in our patients, HFS may be considered as possible cumulative skin toxicity induced by both Sunitinib and Pazopanib.

\section{References}

[1] Ljungberg, B., Cowan, N.C., Hanbury, D.C., et al. (2010) EAU Guidelines on Renal Cell Carcinoma: The 2010 Update. European Urology, 58, 398-406. http://dx.doi.org/10.1016/j.eururo.2010.06.032

[2] Macaluso, M., Montanari, M., Cinti, C., et al. (2005) Modulation of Cell Cycle Components by Epigenetic and Genetic Events. Seminars in Oncology, 32, 452-457. http://dx.doi.org/10.1053/j.seminoncol.2005.07.009

[3] Kruck, S., Merseburger, A.S., Hennenlotter, J., et al. (2012) High Cytoplasmic Expression of p27(Kip1) Is Associated with a Worse Cancer-Specific Survival in Clear Cell Renal Cell Carcinoma. BJU International, 109, 1565-1570. http://dx.doi.org/10.1111/j.1464-410X.2011.10649.x

[4] Hamberg, P., Verweij, J. and Sleijfer, S. (2010) (Pre-)Clinical Pharmacology and Activity of Pazopanib, a Novel Multikinase Angiogenesis Inhibitor. The Oncologist, 15, 539-547. http://dx.doi.org/10.1634/theoncologist.2009-0274

[5] Sonpavde, G. and Hutson, T.E. (2007) Pazopanib: A Novel Multitargeted Tyrosine Kinase Inhibitor. Current Oncology Reports, 9, 115-119. http://dx.doi.org/10.1007/s11912-007-0007-2

[6] Macdonald, J.B., Macdonald, B., Golitz, L.E., Lo Russo, P. and Sekulic, A. (2015) Cutaneous Adverse Effects of Targeted Therapies: Part I: Inhibitors of the Cellular Membrane. Journal of the American Academy of Dermatology, 72, 203-220. http://dx.doi.org/10.1016/j.jaad.2014.07.032

[7] Porta, C., Paglino, C., Imarisio, I. and Bonomi, L. (2007) Uncovering Pandora’s Vase: The Growing Problem of New Toxicities from Novel Anticancer Agents. The Case of Sorafenib and Sunitinib. Clinical and Experimental Medicine, 7, 127-134. http://dx.doi.org/10.1007/s10238-007-0145-8

[8] Bhojani, N., Jeldres, C., Patard, J.J., et al. (2008) Toxicities Associated with the Administration of Sorafenib, Sunitinib and Temsirolimus and Their Management in Patients with Metastatic Renal Cell Carcinoma. European Urology, 53, 917-930. http://dx.doi.org/10.1016/j.eururo.2007.11.037

[9] Miller, K.K., Gorcey, L. and McLellan, B.N. (2014) Chemotherapy-Induced Hand-Foot Syndrome and Nail Changes: A Review of Clinical Presentation, Etiology, Pathogenesis, and Management. Journal of the American Academy of Dermatology, 71, 787-794. http://dx.doi.org/10.1016/j.jaad.2014.03.019

[10] van der Mijn, J.C., Panka, D.J., Geissler, A.K., Verheul, H.M. and Mier, J.W. (2016) Novel Drugs That Target the Metabolic Reprogramming in Renal Cell Cancer. Cancer \& Metabolism, 4, 14.

\section{Submit or recommend next manuscript to SCIRP and we will provide best service for you:}

Accepting pre-submission inquiries through Email, Facebook, LinkedIn, Twitter, etc.

A wide selection of journals (inclusive of 9 subjects, more than 200 journals)

Providing 24-hour high-quality service

User-friendly online submission system

Fair and swift peer-review system

Efficient typesetting and proofreading procedure

Display of the result of downloads and visits, as well as the number of cited articles

Maximum dissemination of your research work

Submit your manuscript at: http://papersubmission.scirp.org/ 